\title{
Is there really a case for Off-Site Manufacturing?
}

\author{
E. Duc, P. J. Forsythe and K. Orr \\ Faculty of Design, Architecture and Building, University of Technology, Sydney, Australia \\ Email: edwardd@ducassociates.com.au
}

\section{Abstract}

The solution often suggested to mitigate poor time, cost and quality in construction is to produce buildings in an automated and industrialised environment. To date, use of Off-Site Manufacturing (OSM) in Australia has enjoyed extremely limited success. Distilling the variables in the success and failure of OSM in other places and applying relevant variables to the Australian context, enables a better response for OSM. The purpose of the paper is therefore to examine whether or not OSM techniques are viable in the Australian housing market. The paper uses a detailed and critical analysis of the literature to examine OSM of housing in various countries, seeking to establish the major reasons for successful and unsuccessful models. The findings are then contrasted with the Australian context seeking criteria to inform successful introduction of OSM into Australia. Among other things, findings indicate the catalyst for the introduction of OSM of housing is almost universally a result of major events such as wars and natural disasters. Innovation has also played a role in encouraging change to construction methods. Whilst the countries addressed have diverse economies and climates compared to each other and Australia, certain common criteria have been found from those examples to assist in modelling an OSM solution in Australia. The implications of this work revolve around the provision of a more efficient, less wasteful and more responsive housing production environment which will potentially improve affordability in the market place.

Keywords

Off-site Manufacturing, housing, drivers and barriers, sustainability, mass customisation

\section{Introduction}

The question as to whether buildings should be produced in factories by off-site manufacture, rather than traditional on-site craft methods has been the subject of numerous papers and industry discussion over a considerable period of time $[1 ; 2]$. Today the question of OSM in Australia, particularly for housing, is being asked more often in an attempt to address issues in the construction industry of saving time, improving quality and better defining cost, as well as greater productivity. It must also noted that extraordinary events outside the industry have created a need to find ways to improve supply of buildings beyond the capability and capacity of the construction industry of the time [3-5]. Further, there are examples of building and construction designers seeking innovation to improve contemporary building construction methods and by-products of the industry. Today, for example, the aspects of sustainability and reduction of waste have evolved, important issues which Barrett and Weidman claim cannot be solved by traditional construction methods [6]. Luther suggests there is evidence that the use of factory production of buildings can solve some of the issues of time, quality and cost, and agrees OSM will enable better levels of sustainability including reduction of waste [7] . In their research for the Royal Institution of Chartered Surveyors (RICS), they go further and suggest traditional construction industry methodology will struggle to solve the challenges of finding meaningful building innovations [8]. Bengtsson nominates a strong barrier to construction innovation is that of institutional path dependency [9]. In contrast, Thuesen and Hvam argue for modifying currently accepted construction methods citing a German example of developing product platforms, an important theoretical but practical position for OSM described later in this paper [10].

For this paper, a clear distinction needs to be drawn between a common term "Modern Methods of Construction" (MMC), used in the construction industry as a descriptive phrase for innovation in construction, and the term OSM [11]. The Building Research Establishment (BRE) defines MMC as a range of processes and technologies which include prefabrication, off-site assembly and various forms of supply chain specifications [12]. For this paper the term MMC is regarded as a broad generic term for innovation in construction techniques, both site and factory based (including OSM) and also encompasses whole-house prefabrication in a factory. Specifically for the genre of OSM, four distinct typologies have been identified by academics and industry, and these categories will inform the relevance of OSM for the Australian market. Bell and Southcombe nominate these categories as component (stick and assembly), panel (non volumetric), module (volumetric), and hybrid (module plus panel) [13].

The use of the term "off-site manufacture" (OSM) is described by Kenley et al and other respected writers on the topic, as embracing various categories for factory manufacture of buildings including off-site fabrication, off-site assembly, off-site construction and 
off-site production [14]. The literature of recent times consistently uses the term OSM to define the use of factories distant from the construction site to produce buildings and building components, and that acronym will be used in this paper $[12 ; 13 ; 15]$.

This paper focuses on the house building construction sector in Australia. The housing sector provides an excellent example for building production to adopt alternative methods (whatever they may be) as a means to satisfy the current demand for housing, which exceeds the supply that conventional traditional methods can provide [16]. It is also relevant for this paper to review OSM of housing in countries where the methodology for manufacture has been developed, the review looks at recent examples to understand current paradigms and technology, and their relevance to the Australian model.

Historically, change from craft to manufacturing in many industries has occurred as a result of innovation. Change also occurs due to major events such as natural disasters or war. This paper will briefly discuss three industries which adopted a regime of factory production and whether that change informs the construction industry in Australia today, particularly addressing the under supply of housing stock described later in this paper.

\subsection{Why consider OSM over Craft Construction?}

Over time, traditional construction methods have failed to satisfactorily address the important criteria for buildings of time, cost and quality, and often for housing a methodology for supply to satisfy demand [8; 16-18].

It is often stated that the last industry to convert to significant factory production is the traditional craft construction industry [19-21]. The Egan Report titled "Rethinking Construction", reviewed the construction industry in the UK positing that though the industry was considered by the community as excellent in execution of complex projects, the industry was under performing, unprofitable and could fall into stagnancy [17]. The Barker Review carried out for the UK government reiterated the same concerns focusing on the decline of housing construction, blaming lack of capacity by the construction industry but also noted a lack of sites for housing caused by factors often, but not always, outside control of the construction industry [22]. The same debilitative issues for construction in the UK prevail in Australia [23; 24]. Failure of the Australian construction industry to address these important issues is reported by The Built Environment Industry Innovation Council's final report (2012), advising the Australian Government on ways to improve the performance of the construction industry and suggesting innovations for the future [25]. Their aims sought to not only improve the performance of the construction industry, but to equip the industry for the future. Importantly this advice also addressed the challenges of climate change and sustainability, and the need to address skills development and the ability to access and accept new technologies where those technologies benefit the industry.

\section{The evolution of craft to manufacturing}

History clearly demonstrates the changes to major craft industries over time. For this paper it is useful to briefly consider relevant examples of transition from traditional means of production to that of manufacturing, and the reasons for those changes which could be described as catalysts for change, and the benefits that flowed for that industry. The examples used in this paper which clearly demonstrate a transition to manufacturing are motor cars, textiles and ships. Gann, when comparing the manufactured housing industry to the automotive industry in Japan, notes that Henry Ford in America exploited the three main advantages of manufacturing over craft to produce motorcars. Those advantages were economies of scale where costs decrease as volumes increase, better use of capital, and better management control. Ford designed production lines which enabled use of semi-skilled and even unskilled workers to operate high-cost specialised machinery to produce motor cars [26]. Traditional vehicle manufacture at the time Ford developed his systems was unable to compete in supply or cost. The vehicles prior to the early $20 \mathrm{C}$ Ford paradigm, were craft constructed horse drawn buggies fitted with an engine.

Also demonstrating the new relationship between workers and machines was the textile industry, often a craft of great pride, often regional in style and requiring varying degrees of skill. Saxonhouse and Wright, in "Technological Evolution in Cotton Spinning, 1878-1933", describe the invention by Compton of the spinning frame which was then commercialised by Arkwright, an English entrepreneur. The spinning frame enabled semiskilled workers to operate machinery to convert raw cotton into mass-produced yarn [27]

The third example of transition from craft to manufacturing is that of shipbuilding, a craft industry right up until the Second World War changed by the advent of the "liberty ships". These ships were produced by US shipbuilders for the UK Government seeking to address the German $U$ Boat attacks on supply ships, seriously threatening essential supplies to the UK. These ships were constructed for a limited life, however the innovation which enabled fast assembly and supply and described by Heskett and Giorgetta, was the use of welding in lieu of rivets, and importantly, the production of modules of hulls for supply to the shipyards where they were assembled [28]. The time to produce the ships decreased from 230 days to 42 days, proving the efficacy of the systems. The ship building revolution continues today for the Korean shipbuilding industry, described by Bock et al as highly advanced and individual customised ships. Bock et al also link this vertical and horizontal evolution of ship building as providing a desirable model relevant and useful to the construction industry [29].

For this paper, the important outcomes are the further development of those industries into mass 
The 31st International Symposium on Automation and Robotics in Construction and Mining (ISARC 2014)

production producing high quality, certainty of costs and variety of product. While there are many other examples of the change from craft to manufacture, the fact remains that building construction is still the last craft industry to follow a long line of predecessors in evolving into a manufacturing model [7]. For the house construction industry to develop a mass production methodology, the logical outcomes must be to replicate the outcomes for the craft to manufacturing examples described, greater supply, greater choice and high quality.

\section{OSM of housing, drivers and barriers}

It is of relevance to this paper to examine and contrast both positive and negative attributes of "prefabrication" of housing in recent history and in various countries. Examples of prefabrication prior to the

$20^{\text {th }}$ century, whilst of interest, are not considered as relevant to a discussion of the use OSM for the provision

of housing in the near

future.

\subsection{Scandinavian OSM of houses}

In Scandinavia and Finland the use of timber construction for houses has been and continues to be their preferred medium. Use of traditional three dimensional timber framed forms and styles familiar to the Scandinavians have been readily transposed into timber-based factory built systems. For Scandinavia, adopting factory based manufacture enables continuous production all year round, thereby defying the harsh winter elements which constrains supply. Waern in "Home Delivery" describes Scandinavia as now being inits third age of prefabrication, the latest iteration that of small lumber companies which have morphed into prefabrication enterprises and are now corporate identities operating internationally $[1 ; 30]$. One group, Skanska/Ikea, is supplying houses to the Scandinavian, Russian and UK markets. The common methodology used for OSM in Sweden is essentially that of transferring traditional site tasks (except for slabs/foundations) into a factory environment, enabling lean construction and acceptable quality, realising time savings through avoiding delays due to poor weather. The growing use of timber volume elements (TVE's) in lieu of the more common assembly of large components could be a potential challenge for OSM of housing in Sweden. TVE's are viewed by the public as "one size fits all", however, the industry has recognized the need for the introduction of mass customisation (MC) and flexibility in design [31]. Lessing et al suggests this need for MC for all typologies of OSM has been recognised in Sweden and is being addressed by housing providers through the use of information and communications technology, and the use of "agile construction". In Sweden $80 \%$ of detached family housing is produced using OSM [32; 33].
For Sweden, drivers are an OSM industry initiated by suppliers of timber materials in a market not dominated by a preference for brick [1] and the advantage of year round production. Success for OSM may also be attributed to the familiarity of the housing forms avoiding issues of path dependency. The size of the market creates economies of scale and therefore affordability compared with traditional sitebuilt housing. Waern (In Home Delivery 2008) states an extreme shortage of housing, dating from 1917, created a major driver for prefabrication in Sweden [30].

\subsection{Germany and OSM of houses}

Linner and Bock estimate 15\% of new house production in Germany is produced by OSM [34]. The manufacture of OSM for housing production in Germany was personally experienced during a visit in 2012. Two different methodologies were observed, Huf Haus using laminated timber post and beam and pre-finished wall and glazing panels, and Massa Haus, using a system of fabricating whole walls and roofs essentially using traditional techniques and materials for later assembly on-site. Both examples when erected on site are capable of achieving weather tightness quickly, but require weeks to complete finishes and services. Huf Haus has adopted a personal face to face with an architect/client design format to produce individual solutions within the post and beam genre, whilst Massa Haus produces different styles to appeal to a broad audience from traditional to "modern". The Huf Haus factory in Hartenfels, I was informed produces 200 houses a year while Massa Haus produces 2000 each year.

The German OSM industry has overcome earlier images of poor quality, initiated by poor perceptions of post war prefabricated house examples. Venables et al states the German OSM industry did this by developing rigorous quality standards with certification schemes to provide client assurance [35]. This negative perception of OSM due to post war prefabricated housing, is widely observed throughout the western world by both the market and the building industry [36; 37]. Venables et al in their study, noted the highly professional promotion of OSM in Germany using among other initiatives, house demonstration villages, which the author experienced and photographed on the visit to Germany in mid 2012 [35]. It is interesting to note the growing use of the concept of product platforms to rationalise production and at the same time satisfy the market need for mass customisation $[38 ; 39]$. For Germany, success has been in part due to satisfying path dependent issues through offering familiar styles and also providing security of quality and durability. Germany has provided security through the establishment of an association (The Association of German Prefabricated Building Manufacturers) (BDF) which requires the quality systems mentioned to be satisfied by its 45 members. 


\subsection{The United States of America and the Development of OSM for Housing}

In the US the use of OSM has a history of varying success and failure. Early OSM in the first half of the $20^{\text {th }}$ century comprised extremely successful kit home examples delivered to the site for assembly, produced by companies offering mail order from catalogues. Sears

Roebuck is probably the most cited company. Mostly using balloon frame construction, (typically timber wall and roof frames pre-made off-site) they were readily erected by builders or owners. Sears sold some 100,000 homes offering 447 different models over a period of 32 years [2]. When the 1930's depression engulfed the world, the housing market stalled and clients defaulted on loans made by Sears. As a result the house businesses of Sears and others failed financially. The US government, as have many governments, encouraged mass production of houses following the second world war, prefabricated houses to satisfy demand which could not be satisfied by the construction industry at the time. This was in part due to a lack of skilled workers due to absent trades serving in the war, but also due to the large number of returning service personnel promised a home by the government on their return [1]. The program was stopped in 1947, and Davies attributes the demise of the prefabricated program for post war housing to the US government [1]. The government demonstrated a preference for traditional methods of on-site production over off-site fabrication, once more demonstrating the perception of a prefabricated house as an inferior product to a site built house. The perception by government and the market, of OSM as an inferior product raises a very large barrier, regardless of the reality.

Two of the better known prefabricated companies in that post world war period encouraged by government programs were Lustron and the General Panel Corporation. Lustron developed from a company which manufactured road side restaurants and service stations using porcelain enamelled metal panels. They transferred this successful technology into a housing model, and reportedly enjoyed a level of success, however, despite significant government funding to underwrite an expensive plant, Lustron was bankrupted holding 20,000 orders but having completed very few of those sales [1] . Well known architects Gropius and Wachsmann designed the Packaged House system for The General Panel Corporation. Bergdoll and Christensen describes its greatest attribute as that of comprising panels which could be used for both walls and floors, representing a considerable reduction in the number of parts reducing complexity, thereby enabling faster assembly and importantly, flexibility in design [2]. The company, although similar to Lustron in the receipt of government financial support, failed to be profitable and ceased manufacture. A significant feature of the Gropius and Wachsmann model was their development of a system with fewer parts than other systems, parts which were interchangeable which enables reduction in the amount of stock holding, and therefore improves the economies
RCHITECTURE

of scale. OSM is currently available in the US, albeit producing a small percentage of the housing stock, that percentage (approximately 3\%) being difficult to fully quantify due to the classification of OSM as manufacturing (including mobile homes) rather than housing [24]. Of the manufactured product which can be classified as detached housing, most examples are volumetric and modular with budgets of between $\$ 200$ to $\$ 250$ per square metre for a completed assembly on site (Budgets were obtained by visiting relevant internet sites). Failures of OSM in the US can be attributed to manufacturing investment too high for the average market house pricing and government's mixed attitudes to prefabricated houses. Lessons from the US for manufactured houses are to resist large infrastructure investment and minimise the number of parts and design flexible systems for customisation.

\subsection{The United Kingdom and its use of OSM for Housing}

In the UK, the evolution of OSM of housing has followed similar precedents of other countries. Construction of housing virtually ceased during the world wars. The housing shortages thus created were exacerbated by returning service personnel from those wars, as well as government slum clearance programs and the replacement of houses demolished during the conflict. Gay and Vale discuss the UK government's action to address the shortages by their establishment of the "UK Temporary Housing Programme" [3; 4]. Under this program the government ordered production of thousands of prefabricated houses in order to satisfy demand for housing which the existing house building industry could not provide within the desired time frame. The brief for the prefabricated houses called for a maximum life span of 10-15 years after which they were to be dismantled. The government was concerned that prefabricated houses should not be construed as site built houses which were regarded as permanent and of better quality. A serious issue for the image of houses produced by prefabrication under the "Temporary Housing Programme", was a lack of variety in their plan and three dimensional form, for all houses were briefed to have two bedrooms and maximum floor space of $800 \mathrm{sq} \mathrm{ft} \mathrm{[3].} \mathrm{This} \mathrm{perception}$ of monotony was sharpened when the prefabricated houses were placed in one area en mass. It should be noted however, that there was acceptance by many of the occupants of the "bungalows" (as they were described) resulting from inclusions of internal bathrooms, allowance for white goods and the added enjoyment of a private garden.

Both Gay and Vale suggest that the UK Government's failure to require some standardisation of components and methods by the various providers, resulted in failure to achieve economies of scale inherent in mass production. Although the plans were almost identical, the manufacturers developed their own systems seemingly to compete and offer a superior system to their competitors in order to gain a 
The 31st International Symposium on Automation and Robotics in Construction and Mining (ISARC 2014) greater market share. The prefabricated housing produced under the "temporary programme" therefore resulted in higher than necessary costs and were unable to challenge standard site constructed housing on a cost basis.

Davies in his book "The Prefabricated Home" refers to the government investing in systems of prefabricated housing during the war periods but reverting to prefer standard site based production once the war was over [1]. Prefabrication in the UK failed to evolve successfully due to public perceptions of poor quality housing, and providing temporary rather than permanent accommodation $[1 ; 3 ; 4]$. In assessing the percentage of OSM compared to onsite for the UK, Goodier and Gibb state they could only make assumptions in order to assess the level of OSM for housing due to lack of reliable statistics of OSM [40]. Currently, despite a large amount of literature endorsing OSM housing, Pan and Sidwell estimate the use of OSM is relatively small in the UK, quoting the entire industry (including all OSM projects) fails to gain more than $6 \%$ of the total market [41]. They place some of the reason for failure on the perception that OSM is more expensive than on-site construction, however note the fallacy of this position through their research which proved otherwise. Significantly, in the UK, house builders rely more upon land sales rather than the construction of houses to make profits, challenging the prospect of OSM further [42]. Pan and Sidwell suggest that there must be continuous exploration and commitment to refining off-site technology and importantly collaboration with the supply chain. The literature alludes to the necessity to change the construction industry to a manufacturing industry if OSM is to succeed. A major reason for this approach lies in the scarcity of skilled tradespeople, Arif et al, go further claiming the benefits of OSM will only be realised when the processes of design, manufacture and construction are completely reengineered. Their research also recommends design flexibility to meet stakeholder needs [43]. Edge et al, in their research into market perceptions, state that the market in the UK does not discriminate in regard to methods of production of houses, but is concerned when the appearance is not traditional [36]. Davies is more critical of the UK market, citing the UK predilection for brick construction and finishes, a material and technology not easily used in OSM [1]. Craig et al address the issue of reluctance to accept OSM housing, suggesting an approach which optimises the economic, ecological and social issues, will reduce that reluctance [44]. Perhaps the prospect for use of OSM for houses in the UK can be best summed up by a visit made by the writer in 2011 to the BoKlok site at Gateshead. What was purported to be an Ikea flatpack housing system was in fact traditional construction, "the flat pack would have been more expensive" was the response from the site foreman.

\subsection{OSM housing in Japan}

Japan has substantially developed the production of OSM for housing. Bergdoll et al argue tradition and

traditional timber construction has given Japan an underlying philosophy encouraging the design and construction of housing using methods of prefabrication [2]. The typical Japanese concept for traditional housing is that of post and beam structure with infill panels. Use of a module was and remains a feature for housing design based on ancient traditions. Development of the post and beam system for OSM housing was described by Oshima in "Home Delivery" as modernisation rather than transformation [45]. Following the Second World War, Japan according to Oshima, had a shortfall of 4.5 million housing units and suffered from the same problems as other countries, that of a lack of skilled trades, many of whom served in the war and of whom many were lost [45]. In addition, significant quantities of their housing stock was destroyed during the war. In contrast however to other major countries, a number of Japanese industrial companies developed housing designs suitable for OSM. From 1959 companies such as Sekisui, Daiwa, National and Misawa produced simple box like houses to meet demand, these companies soon developed more complicated models in order to better compete in the market [46]. Importantly, although economies of scale were found in the size of the Japanese market, those economies were not sufficient to produce houses of less cost than site built houses by local builders. Johnson discusses the approach to offset the cost disadvantage that the factory house builders experienced, by developing solutions which were marketed as having superior performance to the on-site produced houses. In addition the factories offered long term warranties and continuing maintenance. Possibly the most important feature of the Japanese OSM housing industry according to Gann and Barlow et al was the use of a system pioneered by Toyota for manufacture of vehicles [26; 47]. That system called "Kanban" changes the supply chain conventions yielding important concepts of lean production and "just in time" which in turn reduces waste in materials and labour, and further results in less inventory due to greater flexibility and greater variety in product. Barlow et al reinforce Gann's view that the use of mass customisation by the Japanese manufacturers has enabled successful operations despite the cost challenges [47]. The Japanese systems enable house forms which according to Barlow and Oszaki satisfy issues of path dependency in shaping Japan's use of mass customisation in the house building industry [48]. Linner and Bock estimate OSM house production in Japan as $13 \%$ to $15 \%$ of new detached housing per annum [34].

\subsection{OSM in Australia}

For Australia, albeit a country younger and with a population far less proportionally to the countries previously described, the experience for OSM is very similar to those other countries, including various attempts to supplement housing needs using OSM. Greig for example, describes the actions following the second world war by the NSW Housing Commission (a social housing provider) [5]. The Commission obtained some 200 prefabricated house design proposals and constructed 25 test houses from those 
proposals. None were put into production, the Commission claimed the prefabricated houses cost more than "orthodox" dwellings [49]. Another example of the early use of OSM housing was the "The Snowy Mountains Authority" which imported some 4,000 houses from Europe to house workers who migrated to Australia to build the Authorities scheme $[5 ; 50]$. However, the imported houses were generally regarded as unsuitable to the Australian climate having been designed to suit the standards of northern Europe. In Victoria, the State Government, after World War II, converted the Beaufort aircraft factory into a prefabricated house manufacturer. Beaufort Homes represented a 'modern method of housing construction', combining the skills of architect Baldwinson with the technical expertise of the Department of Aircraft Production.. The Federal Government at the time ordered five thousand of those houses for production, however only twentythree were eventually built (State Library of NSW). The reasons for rejecting the Beaufort house were that the homes were smaller in area than comparable site built houses then available, and that they were more expensive [5]. Failure to pursue OSM in the years following the world war was attributed both to a relatively small market and the lack of sufficient industrial capacity and flexibility in Australia. The industry could not overcome the economies of scale needed to produce models which could be cost competitive with site-built housing methods (State Library of NSW). Further, the image of prefabricated houses as that of a temporary dwelling in Australia was similar to that of UK, Germany and the US.

\section{Current issues for Australia}

The question of the use of OSM to produce housing is received with various levels of doubt and confidence world wide, however the focus of this paper is Australia. Unplanned events described earlier have eventuated in Australia due to the current and increasing deficit of the housing supply in Australia [51]. The importance of adoption of OSM for houses in some form, particularly for detached housing, which comprises $77 \%$ of residential accommodation in Australia [52].

For housing worldwide, there is an increasing recognition that the housing sector, both in construction and over their life cycle, is guilty of producing a larger carbon footprint than any other sector [6]. The size of carbon footprint together with the aspects of extreme waste in on-site construction together with low sustainability, needs to be addressed and corrective action taken. Although MMC innovation has been gradually incorporated into on-site construction methods, the methods continue to use relatively standard construction techniques which have been shown to be ineffective in addressing waste and efficient cost effective outcomes. The innovative methods as described by Dalton et al for the Australian house building context hardly qualify for great steps [21]. Firstly, they describe the use of specialist on-site equipment such as nail guns and power saws and the like, secondly, faster communications between the various contractors and sub-contractors through mobile phones, faxes and emails, and thirdly the use of information and communications technologies to enable off-site component manufacture such as roof trusses and complete wall frames. The optimal use of OSM is generally more problematic in terms of uptake. To date, the use and uptake of OSM has been variable in the design and construction of buildings. Limited but increasing success is being realised in commercial applications in Australia. Student, apartment and hospital accommodation constructed by "Quicksmart" is one example of using factory fabricated modules completely finished and craned into position on site. Also finding success in this genre is "Unitised Building", which has recently used similar techniques of factory manufactured modules to construct a number of medium rise apartment buildings in Melbourne. These examples have, according to the two companies achieved successful outcomes for the criteria of timesavings, better quality and cost effectiveness. While there are examples of volumetric modules and whole houses constructed for the detached house market, the volumes thus far produced are incapable of satisfying the market need, and there is no evidence that the industry can substantially improve supply without further innovation [16]. According to Blismas and Wakefield the quantity of OSM detached housing supply in Australia is difficult to estimate [24]. They state there is little definitive evidence available due mainly to a lack of differentiation in the typologies of traditional and OSM approaches, however their estimate is that around 3\% of housing produced in Australia could be defined as OSM. Blismas and Wakefield partially attribute unreliable statistics in Australia to the lack of a peak body to assist in quantifying OSM. This situation may have been recently redressed by the formation of "PrefabAUS", an industry group whose "mission is to represent, showcase and advance the Industry through collaboration, innovation and education" [53]

\section{Questions for the use of OSM, is there a case?}

Although OSM in Australia has been identified by Hampson and Brandon as becoming a significant player in the construction industry by 2020 , there is little evidence this has or will eventuate [16]. It is suggested by Kenley et al that this reluctance for the construction industry to adopt OSM is due to a lack of knowledge of the benefits or understanding of how OSM or MMC could fit into current construction practices [14] This is particularly relevant for the house building industry, not so much the volume builders, but certainly for the majority of house building companies which are classified as small to medium enterprises (SME) working on tight margins. Those SME's are unwilling to accept the perceived additional risk which OSM and MMC creates [54].

In the countries examined for this paper, it is important to note that a severe shortage of housing was the motivation for pursuing OSM for housing. In each case the governments' action, whether it was the US 
The 31st International Symposium on Automation and Robotics in Construction and Mining (ISARC 2014) government's "Operation Breakthrough" (1968-1978), the UK government's "Emergency Housing Programme" (1945-1951) or the Australian government's seeking prefabricated housing solutions, their actions failed. Failure to evolve a successful OSM program was attributed to costs of OSM housing being higher than traditional on-site production. The other major constraint for an ongoing use of OSM were the decisions made by governments to revert to site-built housing using the conventional "craft" skills, based on perceptions of doubtful quality and longevity of OSM. Today, once again, there is a critical shortage of housing in Australia partly due to skills shortages for construction, but mostly due to a reluctance by the construction industry itself to change, whether that genre is MMC or OSM. The relatively successful examples of adoption of MMC or OSM are Sweden, Germany and Japan. The entities producing OSM houses in those countries are manufacturing organisations rather than construction organisations. The indications are that manufacturing in other places will be most likely to realise suitable OSM housing outcomes. This appears to be the case for Australia, it is personally observed that most current OSM producers do not have construction arms, apart from site assembly teams. Lessons for Australia in selling OSM can be learned from Germany and Japan, both having implemented flexibility into their systems through principles of "agile" methods in order to obtain mass customisation rather than mass production. They have done this by seeking customer input at all stages, and they have also adopted quality management and certification. In Japan's case, after sales service and extended warranties also help in off-setting the often higher cost [55] of their OSM housing compared to onsite. These actions thereby address to a significant extent the issues of adverse perceptions of OSM housing the customers, authorities and importantly financial institutions. The Australian market shares with the UK a preference for brick housing solutions [5], a difficult barrier for OSM to overcome. From the literature solutions to negate this path dependency lay with offering high quality together with certainty, and addressing issues of sustainability and waste. The Australian and UK literature nominate design as an important factor, namely that OSM is regarded by industry as requiring early design freeze, and therefore the product lacks flexibility and also incurs expensive penalties for late changes. The solution for the industry is not an easy one, requiring retraining and adoption of new skills to design for manufacture and assembly [56] rather than design for traditional methodology.

Clearly, OSM producers establishing expensive facilities such as occurred for the UK post war "Emergency Housing Programme" and the US examples of Lustron and General Panel Company, risk financial stress. The risk of financial failure is partly due to the cost of the debt, but also the necessity to amortise the debt over potentially limited sales which inflates the cost of the product in many cases to be higher than the site- built product. This is particularly applicable to the Australian market size leading to doubtful economies of scale. Australia can learn from German, Swedish and Japanese OSM producers addressing the supply chain dynamics enabling reduction in stock holdings and timely supply, thus reducing costs. Innovative use of the supply chain permits use of "pull" rather than "push" factors ensuring inventories remain minimal whilst still satisfying the market forces. From Germany and Sweden the concept of product platforms has evolved for OSM housing, a concept in principle similar to the General Panel Companies design for interchangeability of wall and floor panels. This is particularly relevant for Australia, for the concept of components having many uses and configurations enables reduction of the number of components, and therefore cost, and at the same time enables flexibility of design to suit individual briefs. Use of this product platform system reduces costs due to reduction of components required by an OSM system.

\section{Conclusion}

Whilst there is ample evidence in Australia that traditional construction methods cannot supply sufficient housing stock to satisfy current demand, or supply housing to address a significant deficit of some 200,000 houses in Australia [51], there is little evidence of action to innovate and solve the issue of supply. It is clear from other examples of craft industry converting to manufacturing that the products so produced are more affordable, predictable in quantity and quality, and offer offer variety and choice, no such change in the production of housing can be discerned. One factor which does assist in the affordability of manufactured products is reduction of waste. The problem of waste and sustainable practices is clearly one for the production of houses which use traditional on-site methods [6]. There is a great deal of evidence OSM can assist in solving these dilemmas.

While the role of governments is extremely important to the housing industry, particularly the social sector, past experience urges caution and suggests the industry for OSM of housing needs to develop policies to negotiate successful outcomes.

Previously mentioned in this paper, is that the use of OSM in commercial residential has been successfully adopted satisfying the important criteria of time, cost and quality, and it seems the visual form of the finished product being similar to the norm, gains acceptance by the market. For detached housing however, there is limited success in Australia, that success comprising mainly volumetric typologies using traditional methods of assembly within factories, particularly the whole of house fabrication which most often emulates the form and style of traditional housing. These examples demonstrate little innovation, but certainly demonstrate the value of a factory environments for producing houses, typically continuous working conditions unaffected by weather, safer work environments and less waste. However, these volumetric examples are not capable of meeting demand. Successful implementation of OSM in Japan, Scandinavia and Germany 
demonstrates the part played by offering variety including traditional styles.

Examination of successful examples of use of OSM to produce housing has informed this paper. Cost of housing is an important factor and the means of competing with site-built production lays with concepts of lean principles, supply chain innovation and design for manufacture and assembly. Poor perceptions and path dependence create great obstacles to adoption of OSM, however the examples from Germany, Japan and Scandinavia show that use of quality systems, warranties, after sale service and customisation mitigate these negatives. Customisation is possible by the use of multi use components and the design of product platforms. These methods also enable a OSM system to more easily satisfy economies of scale. Importantly there is the question of what form the OSM production groups should take. In the US but particularly the UK, the providers of OSM are seen as members of the construction industry. The evidence from successful OSM industries is that the proponents are manufacturing based.

For the OSM industry there are new technologies and innovative materials such as plug and play fittings for services, and new methods of production available such as CAD/CAM systems for manufacture of components. There are smart foundation methods which do not require excavation or in-situ concrete. These innovative systems will offer the edge over onsite construction sufficient for OSM to develop into a relevant and profitable industry in Australia.

\section{References}

[1] Davies, C., 2005. The Prefabricated Home. Reaktion Books.

[2] Bergdoll B. Waern, R. Oshima. K. Broadhurst, R. (Ed.), 2008. Home Delivery; Fabricating the Modern Dwelling. The Museum of Modern Art, New York.

[3] Gay, O. (1987). Prefabs: A Study in Policy-Making, Public Administration (65) Winter 1987: 407-422.

[4] Vale, B. Alexandrine Press, O. (Ed.), 1995. Prefabs: A history of the UK Temporary Housing Programme. E and FN Spon.

[5] Greig, A. W., 1995. The Stuff Dreams Are Made Of: Housing provision in Australia 1945-1960. Melbourne University Press, Carlton, Victoria 3053.

[6] Barrett J. Wiedmann, T. (2007). A Comparative Carbon Footprint Analysis of On-Site Construction and an Off-Site Manufactured House.

[7] Luther, M. (2012). A new paradigm for sustainable residential buildings, 1252-1258.

[8] Goodier, C. and Pan, W. (2010). The Future of UK Housebuilding.

[9] Bengtsson, B. (2009). Applying Path Dependence Perspectives in Housing Studies.

[10] Thuesen, C. and Hvam, L. (2011). Efficient on-site construction: learning points from a German platform for housing, Construction Innovation: Information, Process, Management 11: 338-355.

[11] Pan W. Gibb and A. Dainty. R. (2007). Perspectives of UK Housebuilders on the use of OffSite Modern methods of Construction. Construction Management \& Economics 25: 183-194.

[12] Smith R.A., Kersey. J. and Giffiths. P. (2009). Be Aware, Improving Resource Efficiency in Construction Product Manufacture.

[13] Bell P. Southcombe, M., 2012. Kiwi Prefab: Auckland New Zealand.

[14] Kenley, R., Kanjanabootra, S., Ouyang, C., and Wynn, M. (2012). Procuring OSM: Base-Line Models of Off-Site Manufacture Business Processes In Australia, 16th Pacific Association of Quantity Surveyors Congress, Innovating, and Sustaining: Challenges and Opportunities.

[15] Pan, W, Gibb, A and Dainty, A. (2008). Leading UK Housebuilders' Utilisation of Offsite Construction Methods., Building Research and Information 36 (1): 5667.

[16] Hampson K. and Brandon, P. (2004). Construction 2020. A Vision for Australia's Property and Construction Industry.

[17] Egan, S. J. (1998). Rethinking Construction.

[18] Goulding, J.; Rahimian, F. P.; Arif, M. and Sharp, M. (2012). Offsite Construction: Strategic Priorities for Shaping the Future Research Agenda, Architectoni.ca 1:62-73.

[19] McKean, J. (2006). Prefabricating Memory Lane: Whatever Happened to Systems?, AD 76 : 56-59.

[20] Engstrom S. and Hedgren, E. (2012). Sustaining Inertia?: Construction Clients' decision-making and information-processing approach to industrialised building innovations., Construction Innovation: Information, Process, Management. 12(4) : 393-413.

[21] Dalton, T., Hurley, J., Gharaie, E., Wakefield, R., and Horne, R (2013). Australian suburban house building: industry organisation, practices and constraints, Australian Housing and Urban Research Institute Positioning Paper Series 1-56.

[22] Barker, K. (2005). Using Modern Methods of Construction to Build Homes More Quickly and Efficiently.

[23] Blismas N. Pasquire, C. and Gibb. A. (2007). Benefit Evaluation for Off-Site Production in Construction, Construction Management and Economics 24: 121130.

[24] Blismas, N. and Wakefield, R. (2009). Drivers, constraints and the future of offsite manufacture in Australia, Construction Innovation: Information, Process, Management 9: 72-83.

[25] Built Environment Industry Innovation Council 
The 31st International Symposium on Automation and Robotics in Construction and Mining (ISARC 2014)

(2012). Final Report to the

Government.

[26] Gann, D. M. (1996). Construction as a manufacturing process? Similarities and differences between industrialised housing and car production in Japan., Construction Management and Economics 14: [27] Saxonhouse, G. and Wright, G. (2000). Technological evolution in cotton spinning, 1878-1933, Economics Department Working Paper Series, Stanford University.

[28] Heskett, J. and Giorgetta, A., (1980). Industrial design. Thames and Hudson London,

[29] Bock, T.; Linner, T. and Eibisch, N. (2011). Vertical Shipyard: Technology Transfer for Automated Con-and Deconstruction.

[30] Waern, R.Broadhurst, R. (Ed.), 2008. Home Delivery; Fabricating the Modern Dwelling. The Museum of Modern Art, New York.

[31] Hook, M. (2006). Customer value in Lean Prefabrication of Housing Considering both Construction and manufacturing.

[32] Lessing J. Stehn, L. E. A. (2005). Industrialised Housing: Definition and Categorisation of the Concept, Prefabrication, Assembly and Open Building.

[33] SCB Statistics Sweden.

[34] Linner, T. and Bock, T. (2012). Evolution of largescale industrialisation and service innovation in Japanese prefabrication industry, Construction Innovation: Information, Process, Management 12: 156-178.

[35] Venables T. Barlow, J. Gann. D. (2004). Manufacturing Excellence UK capacity in offsite manufacturing.

[36] Edge, M., Craig, A., Laing, R., Abbott, L., Hargreaves, A., Scott, J. and Scott, S. (2002). Overcoming Client and Market Resistance to Prefabrication and Standardisation in Housing, Robert Gordon University, Aberdeen.

[37] Koebel, C. T. (2008). Innovation in Homebuilding and the Future of Housing, Journal of the American Planning Association 74: 45-58.

[38] Veenstra, V. S., Halman, J. I. and Voordijk, J. T. (2006). A methodology for developing product platforms in the specific setting of the housebuilding industry, Research in engineering design 17: 157-173.

[39] Halman, J. I.; Voordijk, J. T. and Reymen, I. M. (2008). Modular approaches in Dutch house building: an exploratory survey, Housing Studies 23: 781-799.

[40] Goodier C. and Gibb, A. (2007). Future Opportunities for Offsite in the UK. Construction Management \& Economics 25: 585-595.
[41] Pan, W. and Sidwell, R. (2011). Demystifying the cost barriers to offsite construction in the $U K$,

[42] Miles, J. and Whitehouse, N. (2013). Offsite Housing Review.

[43] Arif, M.; Goulding, J. and Rahimian, F. P. (2012). Promoting Off-Site Construction: Future Challenges and Opportunities, Journal of Architectural Engineering 18: 75-78.

[44] Craig, A.; Laing, R. and Edge, M. (2000). The social acceptability of prefabrication and standardisation in relation to new housing 4-7.

[45] Oshima, K. and Broadhurst, R. (Ed.), 2008. Home Delivery; Fabricating the Modern Dwelling. The Museum of Modern Art, New York.

[46] Johnson, W. (2007). Lessons from Japan: A comparative study of the market drivers for prefabrication in Japanese and UK private housing development.

[47] Barlow, J., Childerhouse, P., Gann, D., Hong-Minh, S., Naim, M. and Ozaki, R. (2010). Choice and delivery in housebuilding: lessons from Japan for UK housebuilders, Building research \& information 31: 134145.

[48] Barlow, J. and Ozaki, R. (2004). Building mass customised housing through innovation in the production system: lessons from Japan, Environment and Planning A 37: 9-20.

[49] Australian Institute of Policy and Science (1947).

[50] Cobbers A Jahn, O.Gossel, P. (Ed.), 2010.

Prefab.Taschen,

[51] Donald, O. (2012). State of Supply

Report. [52] Australian Bureau of Statistics

(2012).

[53] Backhouse, S. (2013).

PrefabAUS

[54] Manley, K. (2006). The innovation competence of repeat public sector clients in the Australian construction industry, Construction Management and Economics 24: 1295-1304.

[55] Richard, R. B. (2006) Industrialized, Flexible and Demountable Building Systems Quality, Economy and Sustainability CRIOCM 2006 International Symposium, 2006

[56] Pasquire, C. L. and Connolly, G. E. (2003). Design for manufacture and assembly, 184-194. 